\title{
Dyspnea in Takayasu arteritis - an ordinary cause with an extraordinary link
}

\begin{abstract}
Takayasu arteritis (TA) poses a diagnostic challenge as it may have a myriad of clinical presentations. Dyspnea, as an index presentation in TA, may be secondary to the involvement of the aorta, myocardium, and/or the pulmonary vessels, or can present as a manifestation of pulmonary infection with tuberculosis. Significant lymphadenopathy cannot be attributed to TA and serves to point towards a different diagnosis or concomitant infection. Tuberculosis has been associated with TA and has considerable pathogenic and therapeutic implications. We present a case of a young female with extensive intra-thoracic tubercular lymphadenopathy compressing the trachea and right main bronchus resulting in dyspnea. The patient was subsequently found to have active TA and improved after treatment with anti-tubercular therapy and steroids. We review the causes of dyspnea and mediastinal lymphadenopathy in a patient with TA.
\end{abstract}

Key words: Takayasu arteritis, extra-pulmonary tuberculosis, dyspnea

Adv Respir Med. 2021; 89: 63-67

\section{Introduction}

Takayasu arteritis (TA) is a large vessel vasculitis that preferentially affects young females of Asian origin. It classically presents with intermittent claudication and asymmetry in pulse volume between the limbs due to its predilection for the aorta and its branches. Dyspnea is uncommon and can be attributed to the involvement of the aorta, myocardium, and/or pulmonary vessels. It may also be caused by pulmonary infection with tuberculosis and, as in the present case, by extrinsic airway compression due to mediastinal lymphadenopathy.

\section{Case}

A 16-year-old girl presented with acute onset dyspnea on exertion (mMRC class III) along with a dry cough and low-grade fever for one week. There was no postural or diurnal variation in the dyspnea, no sputum production, and the patient did not have contact with a patient with tuberculosis. She had a history of intermittent claudication of both legs on walking more than 500 meters. On examination, the respiratory rate was $28 / \mathrm{min}$ and breath sounds were reduced on the right side without audible wheezes or crepitations. On percussion, resonance was noted on the right side. Peripheral pulses were not palpable in the upper limbs, and only feeble pulsations were felt in bilateral femoral and popliteal arteries. Correspondingly, blood pressure was not recordable in either upper limb and was asymmetric between the two lower limbs $(80 / 40 \mathrm{~mm} \mathrm{Hg}$ in the left vs $110 / 70 \mathrm{~mm} \mathrm{Hg}$ in the right). Bruits were audible over the right brachial artery, abdominal aorta, and right femoral artery. There was no pedal edema or neck vein distention, and cardiac auscultation was normal.

The patient's feeble pulses and low blood pressure initiated emergency fluid resuscitation protocols. Laboratory investigations revealed anaemia (haemoglobin $10.3 \mathrm{~g} / \mathrm{dL}$ ), leukopenia (2380 cells $/ \mathrm{mm}^{3}$ ), and elevated inflammatory markers with an erythrocyte sedimentation rate of

Address for correspondence: Animesh Ray, All India Institute of Medical Sciences, Ansari Nagar, New Delhi, India; e-mail: doctoranimeshray@gmail.com 
$60 \mathrm{~mm} / \mathrm{h}$ and C-reactive protein levels of $13 \mathrm{mg} / \mathrm{dL}$ (normal $<5 \mathrm{mg} / \mathrm{dL}$ ). For suspected vasculitis, we tested for rheumatoid factor, anti-nuclear antibodies, anti-neutrophil cytoplasmic antibodies, and antibodies to double-stranded DNA, along with serologies for HBV, HCV, syphilis, and HIV, which were all negative. Urinalysis was bland, without proteinuria, hematuria, or casts. Renal artery doppler screening ruled out significant renal artery stenosis. ECG and bedside echocardiographic examination ruled out left venticular (LV) systolic dysfunction, pulmonary hypertension, and stenosis.

A chest X-ray revealed bulky lymph nodes (Figure 1). A subsequent contrast-enhanced computed tomography (CECT) scan showed necrotic conglomerated and lobulated lymph nodes up to $7.5 \mathrm{~cm}$ in diameter, located in the subcarinal and paratracheal locations, with compression of the trachea and right main bronchus (Figure 2). A tubercular aetiology of these lymph nodes was suggested by the presence of tiny well-formed granulomas with necrosis on endobronchial-ultrasound-guided transbronchial node aspiration (EBUS TBNA). GeneXpert ${ }^{\mathrm{TM}}$ from the TBNA was positive for rifampicin-sensitive tuberculosis.

Magnetic resonance angiography (MRA) confirmed diffuse $(60 \%)$ stenosis of the upper infrarenal abdominal aorta and occlusion of bilateral subclavian arteries with distal reformation suggestive of aortoarteritis (Figure 3). She fulfilled all six of the American College of Rheumatology (ACR) criteria and was thus diagnosed with TA. She was also diagnosed with extra-pulmonary tuberculosis. She was treated with a combination of corticosteroids (prednisone at $1 \mathrm{mg} / \mathrm{kg}$ for six weeks, followed by a slow taper over nine to twelve months) and anti-tubercular therapy (ATT, nine months). Repeat CT imaging at one year showed near resolution of lymph nodes (size $7.5 \mathrm{~cm}$ decreased to $1.5 \mathrm{~cm}$ ), and an MRA confirmed reduction in disease activity with an increase in luminal patency. The patient is doing well at 1 year of follow-up without symptoms of claudication, cough, or dyspnea.

\section{Discussion}

Tuberculosis' association with TA is not only a medical curiosity, but is also thought to play a role in the immunopathogenesis of TA. A systematic review evaluating this association found a high prevalence of active tuberculosis (16\%) and latent tuberculosis (59\%) in patients with TA, far higher than the general population [1]. They hypothesized that a loss of tolerance against self-

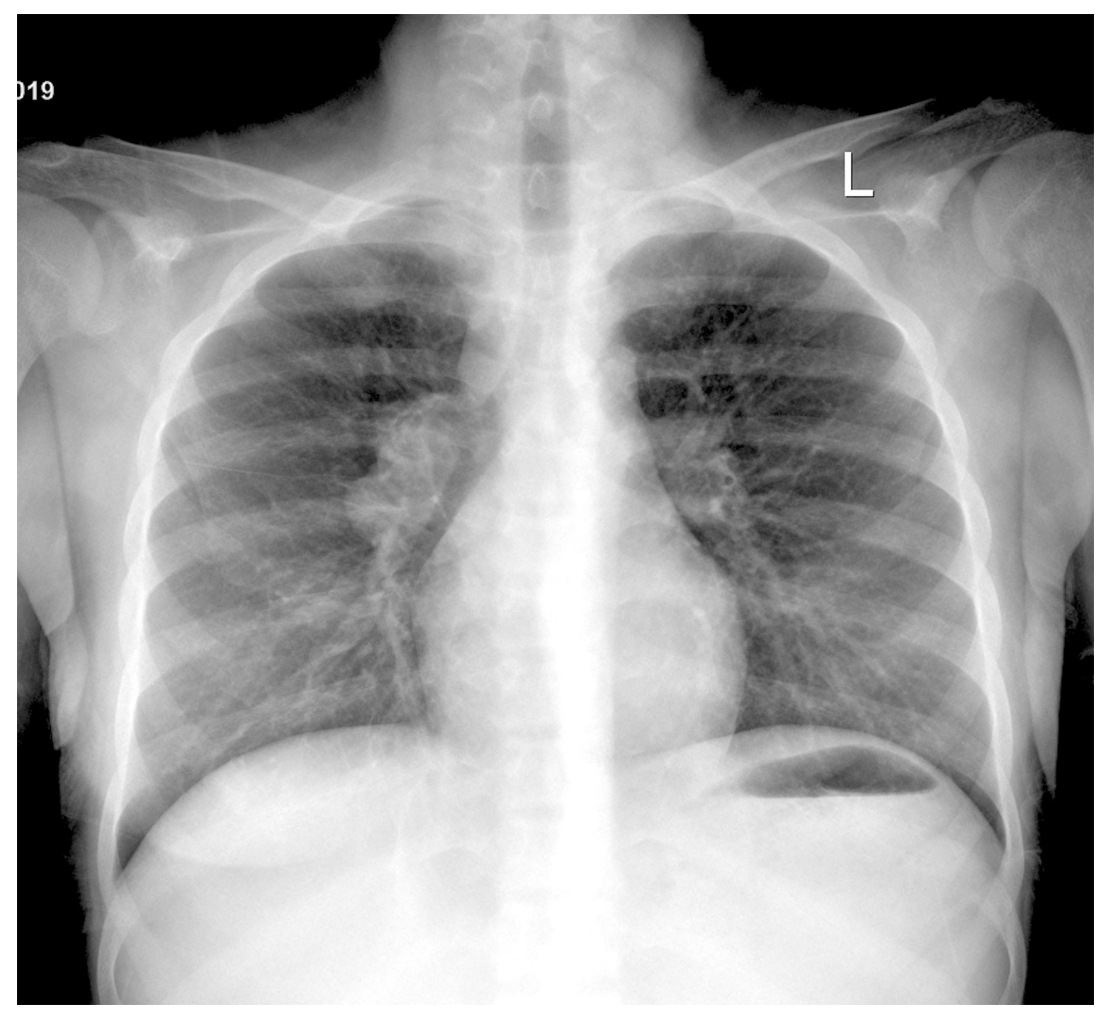

Figure 1. Chest X-ray posteroanterior view showing bulky hilum on the right side $>$ left side with well defined enlarged lymph nodes, right paratracheal stripe thickening, and normal lung parenchyma. The right lower lobe bronchus appears to be narrowed without significant collapse 


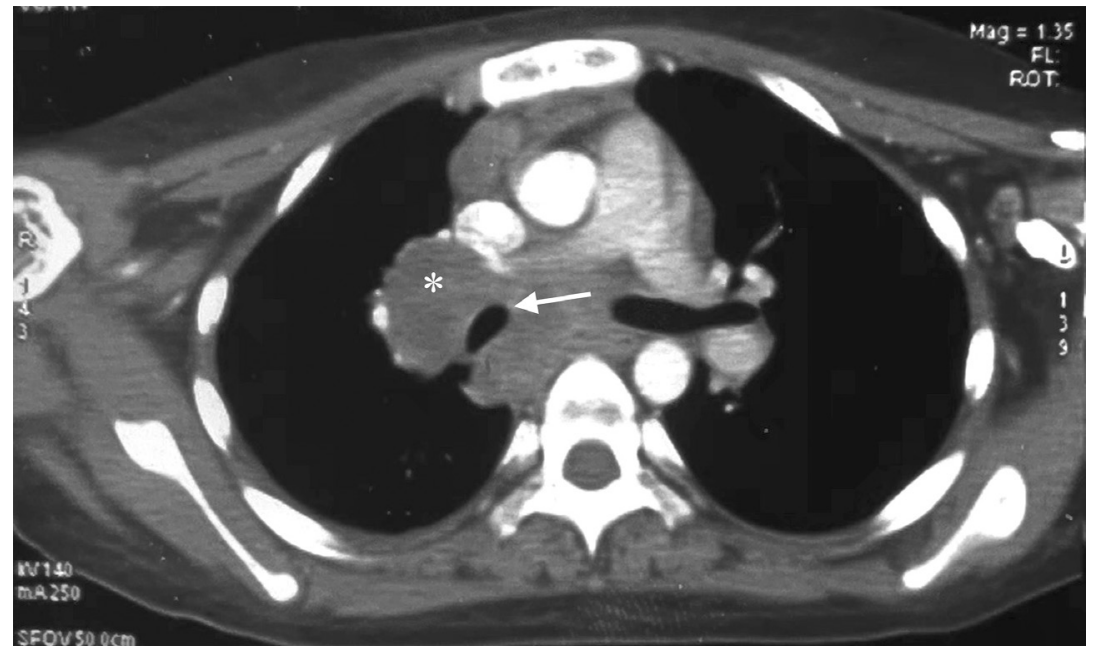

Figure 2. Contrast-enhanced computed tomography chest showed conglomerated lobulated lymph nodes with necrotic core in subcarinal and paratracheal location, the largest measuring $7.5 \times 7.5 \mathrm{~cm}$ (asterisk), compressing the trachea and right main bronchus (arrow)

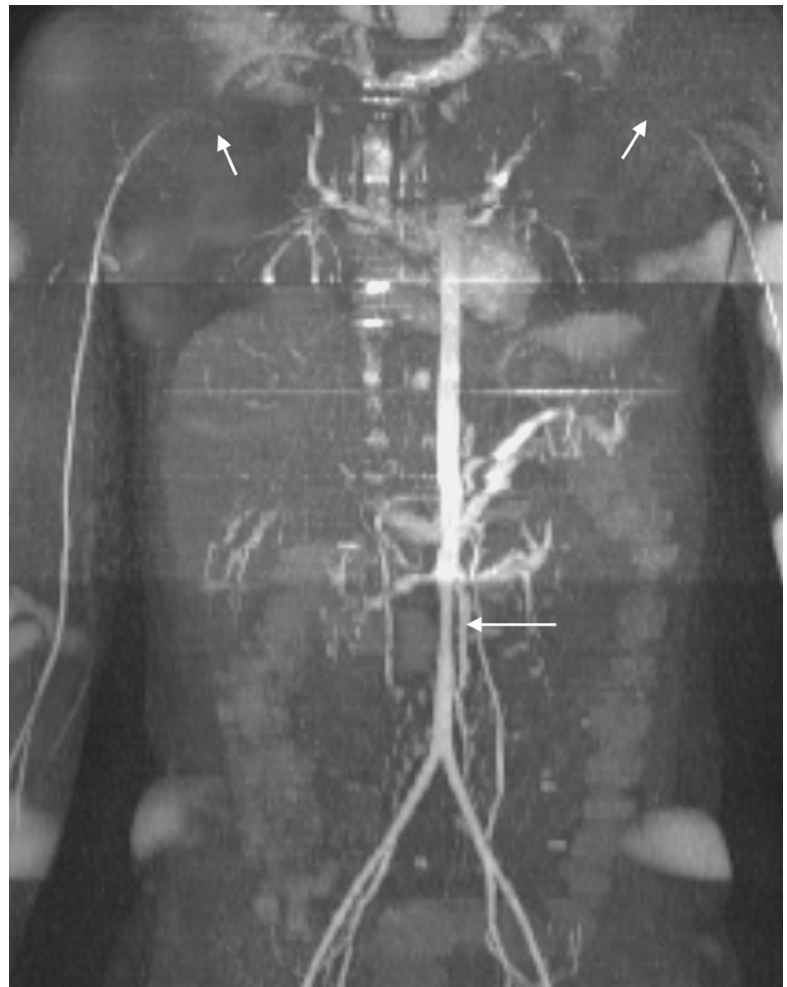

Figure 3. Magnetic resonance angiography revealed diffuse $(60 \%)$ stenosis of the upper infrarenal abdominal aorta, occlusion of bilateral subclavian artery with distal reformation suggestive of aortoarteritis

stress proteins is the main pathogenic event in TA, and the extensive sequence homology between mycobacterial and human stress proteins leads to epiphenomenal cross-reactions.

Treating these conditions simultaneously with corticosteroids and ATT is effective. Use of corticosteroids does not increase the risk of microbiological failure of ATT in pulmonary tu- berculosis [2]. TNFa inhibitors have been used in steroid-refractory TA with an extremely low risk of reactivation of latent tuberculosis $(0.9 \%)$ similar to other rheumatic disorders [3]. This suggests that the association between TA and tuberculosis is predominantly epi-phenomenal, instead of a result of latent infection.

There are several mechanisms by which patients with TA can manifest dyspnea (Table 1). A previous case reported dyspnea as the index presentation which was attributed to the involvement of pulmonary arteries [4]. Pulmonary arterial involvement on pathological examination occurs in half of the cases but is rarely symptomatic. Since it presents with progressive dyspnea and angina, chronic thromboembolic pulmonary hypertension should be kept as a differential. Systolic cardiac failure resulting from dilated cardiomyopathy, with or without histological evidence of myocarditis, may be the first presentation of TA [5]. Other cardiovascular complications resulting in dyspnea include aortic regurgitation secondary to aortic root dilation [6] and acute myocardial infarction [7].

Lymphadenopathy cannot be attributed to TA alone. However, aortitis with concomitant lymphadenopathy narrows the list of differentials (Table 2). In patients with underlying TA, lymphadenopathy may be coincidental due to infections or malignancy, but the occurrence of tuberculosis is more likely. Lymph node involvement was present in 14\% (16 out of 110) of adult cases of TA with active tuberculosis identified in the above-mentioned systematic review [1]. One must also consider that a distinct disease process resulted in the aortitis and lymphadenopathy exemplified by tubercular aortitis [8], 
Table 1. Causes of dyspnea in patients with Takayasu arteritis

\begin{tabular}{|c|c|c|c|c|}
\hline No. & Cause of dyspnea & Characteristics of dyspnea & Diagnosis & References \\
\hline 1 & $\begin{array}{l}\text { Pulmonary artery stenosis/ } \\
\text { /pulmonary hypertension }\end{array}$ & Gradual onset, mild, exertional & CT or MRA, lung perfusion scan & [4] \\
\hline 2 & $\begin{array}{l}\text { Congestive heart failure } \\
\text { (dilated cardiomyopathy, } \\
\text { with or without myocarditis) }\end{array}$ & $\begin{array}{l}\text { At rest or exertion, orthopnea, } \\
\text { nocturnal; gradual or acute; } \\
\text { crepitations, LV S3, pedal oedema }\end{array}$ & $\begin{array}{l}\text { ECHO, rndomyocardial biopsy, } \\
\text { pro-BNP/NT-pro BNP }\end{array}$ & [5] \\
\hline 3 & Aortic insufficiency & $\begin{array}{l}\text { Gradual, mild to severe, } \\
\text { exertional; angina }\end{array}$ & $\begin{array}{c}\text { Echocardiogram, cardiac CT } \\
\text { or MRI scan }\end{array}$ & [6] \\
\hline 4 & Acute myocardial infarction & $\begin{array}{c}\text { Acute, at rest or exertion, orthopnea, } \\
\text { nocturnal; crepitations, LV S3, } \\
\text { pedal oedema }\end{array}$ & $\begin{array}{l}\text { Cardiac troponins, ECG, } \\
\text { angiography }\end{array}$ & [7] \\
\hline 5 & $\begin{array}{l}\text { Tuberculosis-pulmonary } \\
\text { or extra-pulmonary }\end{array}$ & $\begin{array}{l}\text { Gradual, exertional; wheeze } \\
\text { or decreased air entry, cough, } \\
\text { hemoptysis, fever, night sweats }\end{array}$ & $\begin{array}{c}\text { Sputum examination, chest X-ray, } \\
\text { HRCT chest }\end{array}$ & $\begin{array}{c}{[1],} \\
\text { present case }\end{array}$ \\
\hline
\end{tabular}

Table 2. Causes of lymphadenopathy in a patient with aortitis

\begin{tabular}{|c|c|c|c|c|}
\hline No. & Cause of lymphadenopathy & Characteristics & Diagnosis & References \\
\hline 1 & Tuberculosis & $\begin{array}{c}\text { Directly due to tubercular aortitis, } \\
\text { or due to concomitant TA }\end{array}$ & $\begin{array}{l}\text { Lymph node biopsy, ZN staining, } \\
\text { CB-NAAT, liquid culture }\end{array}$ & [8] \\
\hline 2 & IgG4 related disease & $\begin{array}{l}\text { Thoracic: males, aortic arch, } \\
\text { lymphoplasmacytic infiltrate, more severe. } \\
\text { Inflammatory abdominal aortic aneurysms: } \\
\text { less severe, lower lgG4 levels }\end{array}$ & $\begin{array}{l}\text { Lymph node biopsy: HPE } \\
\text { with staining for lgG4 + cells, } \\
\text { serum lgG4 levels }\end{array}$ & [9] \\
\hline 3 & Syphilis & $\begin{array}{l}\text { Quaternary syphilis, often causes aortic } \\
\text { root aneurysm, aortic regurgitation }\end{array}$ & $\begin{array}{l}\text { Treponemal and non-treponemal } \\
\text { serology }\end{array}$ & {$[10]$} \\
\hline 4 & Sarcoidosis & $\begin{array}{l}\text { Middle-aged, often with myocardial } \\
\text { involvement }\end{array}$ & $\begin{array}{l}\text { Lymph node biopsy, serum } \\
\text { ACE levels, serum and urinary } \\
{\left[\mathrm{Ca}^{2+}\right] \text { levels, Bronchoalveolar }} \\
\text { lavage (CD4: CD8 ratio) }\end{array}$ & {$[11]$} \\
\hline
\end{tabular}

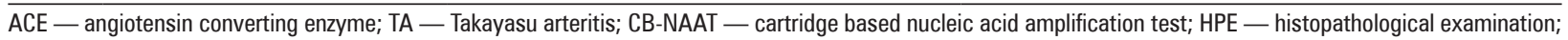
ZN — Ziehl-Neelsen stain

IgG-4 disease-related periaortitis [9], syphilitic aortitis [10], and possibly sarcoidosis [11]. The visualization of necrotizing granulomas and AFB, or a positive GeneXpert ${ }^{\mathrm{TM}}$ from nodal tissue, as found in our case, establishes the diagnosis of tubercular lymphadenopathy.

Our patient presented with extrinsic airway compression by large mediastinal lymph nodes which was eventually attributed to tuberculosis. Further evaluation confirmed active TA necessitating appropriate treatment for both conditions with steroids and ATT. To the best of our knowledge, this unusual cause of dyspnea in $\mathrm{TA}$ is the first in literature.

\section{Conclusions}

Takayasu arteritis possibly results from an epi-phenomenal cross-reaction with tubercular and human stress proteins, and these patients often have active or latent tuberculosis at presentation. TA patients with dyspnea should be evaluated for cardiac, pulmonary, and vascular involvement, as well as pulmonary tuberculosis or mediastinal lymphadenopathy.

\section{Conflict of interest}

None declared. 


\section{References:}

1. Pedreira AL, Santiago MB. Association between Takayasu arteritis and latent or active Mycobacterium tuberculosis infection: a systematic review. Clin Rheumatol. 2020; 39(4): 1019-1026, doi: 10.1007/s10067-019-04818-5, indexed in Pubmed: 31729680.

2. Critchley JA, Orton LC, Pearson F. Adjunctive steroid therapy for managing pulmonary tuberculosis. Cochrane Database Syst Rev. 2014(11): CD011370, doi: 10.1002/14651858.CD011370, indexed in Pubmed: 25387839.

3. Castillo-Martínez D, Amezcua-Castillo LM, Granados J, et al. Is Takayasu arteritis the result of a Mycobacterium tuberculosis infection? The use of TNF inhibitors may be the proof-of-concept to demonstrate that this association is epiphenomenal. Clin Rheumatol. 2020; 39(6): 2003-2009, doi: 10.1007/s10067020-05045-Z, indexed in Pubmed: 32198554.

4. Neidhart B, Kosek R, Bachmann LM, et al. Exertional dyspnea as initial manifestation of Takayasu's arteritis - a case report and literature review. BMC Pulm Med. 2001; 1: 3, doi: 10.1186/1471-2466-1-3, indexed in Pubmed: 11801196.

5. Talwar KK, Kumar K, Chopra P, et al. Cardiac involvement in nonspecific aortoarteritis (Takayasu's arteritis). Am Heart J. 1991; 122(6): 1666-1670, doi: 10.1016/0002-8703(91)90285-p, indexed in Pubmed: $\underline{1683519}$.
6. Alali WM, Alahmari SA, Alhebaishi YS, et al. Severe aortic regurgitation complicating Takayasu's arteritis. Saudi Med J. 2017; 38(8): 863-867, doi: 10.15537/smj.2017.8.12473, indexed in Pubmed: 28762441.

7. Saxena A, Sontakke TR, Mishra D, et al. Acute myocardial infarction with left ventricular failure as an initial presentation of Takayasu's arteritis. J Clin Diagn Res. 2016; 10(5): OD27-OD28, doi: 10.7860/JCDR/2016/16930.7817, indexed in Pubmed: 27437287.

8. Mally A, D'Souza C, Dwivedi S, et al. Pulmonary tuberculosis with multiple saccular aneurysms of the aorta--a case report. Angiology. 1990; 41(4): 333-336, doi: 10.1177/000331979004100411, indexed in Pubmed: 2339830.

9. Stone JR. Aortitis, periaortitis, and retroperitoneal fibrosis, as manifestations of IgG4-related systemic disease. Curr Opin Rheumatol. 2011; 23(1): 88-94, doi: 10.1097/BOR.0b013e3283412f7c, indexed in Pubmed: 21037477.

10. Drago F, Merlo G, Rebora A, et al. Syphilitic aortitis and its complications in the modern era. G Ital Dermatol Venereol. 2018; 153(5): 698-706, doi: 10.23736/S0392-0488.16.05522-X, indexed in Pubmed: 27982548.

11. Wang L, Omari A, Emmett L, et al. Granulomatous sarcoid aortitis: a serious complication of a well-known multisystem disease. The Lancet. 2015; 385(9981): 2014, doi: $10.1016 /$ s0140-6736(15)60649-3. 